\title{
IMPROVING THE BENDING STRENGTH OF SPUR GEAR TOOTH THROUGH PROFILE MODIFICATION USING CAD
}

\author{
SUSWANTH POLURU ${ }^{1} \&$ VIJAY PANDEY ${ }^{2}$ \\ ${ }^{1}$ Department of Mechanical Engineering, Birla Institute of Technology, Mesra, Ranchi, Jharkhand, India \\ ${ }^{2}$ Department of Production Engineering, Birla Institute of Technology, Mesra, Ranchi, Jharkhand, India
}

\begin{abstract}
Undercutting is one of the major tooth failure criteria, observed basically in 20-degree pressure angle, full depth teeth, having number of teeth less than 17 in case of spur gears. Undercutting removes the root of tooth, which causes bending of tooth, leading to tooth breakage at root portion. This work is focussed on avoiding undercutting problems by minimizing the bending stress that occurs at the root portion of the tooth. The method of Profile Modification is taken as the corrective measure to minimize the bending stress at the root. A spur gear having 14 numbers of teeth was modelled in CATIA V5 and a single spur gear tooth was considered for Finite Element Analysis as per the Lewis Model for investigating bending stress in ANSYS 16.0 Workbench.

In this paper, the three parameters, Profile Radius, Root Radius and Face width were optimized. Profile Radius and Root Radius were optimized, which yielded better results of bending stress reduction. But, when Face width was taken into consideration, there was tremendous reduction in bending stress, leading to better improvement in the bending strength of the tooth, which can minimise undercutting problems and avoid tooth breakage.

KEYWORDS: Undercutting, Profile Modification, Profile Radius, Root Radius, Face Width, Bending Strength \& Lewis Model
\end{abstract}

Received: Jun 16, 2017; Accepted: Jun 30, 2017; Published: Jul 04, 2017; Paper Id: IJMPERDAUG20175

\section{INTRODUCTION}

Gears are toothed wheels, which transmit power and motion between shafts, by successive engagement of teeth. Spur Gears are the simplest among all other categories of gears, because of their simple design. These gears have straight teeth parallel to the axes, due to which they are often subjected to sudden application of loads, high impact stresses and excessive noise at high speeds. This weakens the teeth and greatly reduces the efficiency of the gears and leads to undercutting of teeth and fatigue failures.

Undercutting is cutting or removal of the interfering portion of the flank of the tooth, which occurs due to bending stresses acting at the root portion of the tooth. While fatigue failure is caused by the breakage of the tooth at the root in repeating conditions of bending, stresses at the root fillet portion of the tooth [1]. In order to avoid these failures, it is suggested to sparse the stress concentration from the root area of the tooth. Application of Stress Relieving Features (SRFs) at stress concentration area and Profile Modification of the Involute profile of gear tooth are two popular methods to relieve the stresses from the tooth. But, SRFs has a limitation as the stress field is highly sensitive to location and size of the SRF. If these parameters are not well controlled, insertion of SRF may affect adversely. Hence, the method of Profile Modification is employed to relieve the stresses from the tooth in the present 
work.

\section{BACKGROUND}

The application of Profile Modification was first introduced by H. Walker in 1940 in his work, 'Gear Tooth Deflections and Profile Modifications' in which, he considered tooth deflection in evaluation of tooth load and proposed a trapezoidal tooth load cycle, which helped to estimate the amount of tip relief and its extension along the tooth profile (Bonori et al,2008). Later, it became the interest of researchers as it outperforms other methods to improve the stress concentrations [ref of review paper]. This section is devoted to the available literatures pertaining to the application of profile modification.

V. Senthil Kumar et al (2008), studied the effect of pressure angle, top land thickness, profile shift and speed ratio on the fillet stresses and suggested optimum values of these parameters to improve fillet capacity in bending. Shanming Luo et al (2008), developed the mathematical model and equation of cosine curve as a tooth profile for pinion of the drive and confirmed that the cosine gear drive has lower sliding coefficients and contact and bending stresses are reduced. Jian Wang et al (2009), derived the mathematical model of tooth profiles based on small sliding coefficients to improve wear and friction properties and raised the life span of gears. A. Kapelevich \& Y. Shekhtman (2009), said gear tooth fillet is an area of maximum bending stress concentration and presented a fillet profile optimization technique to reduce bending stress, which traded for higher load capacity, longer lifetime, lower noise and vibration and cost reduction. V. Spitas et al (2009), used several tooth designs as an alternative to reduce tooth fillet stresses, which lead to increase in load carrying capacity. V. Simon (2009), introduced optimal modifications in gear tooth surfaces, based on optimal corrections of profile. This leads to favourable load distribution and reduced transmission error. I.D. Paul and G.P. Bhole (2010), studied the effect of tooth relief modification of involute gear system, to reduce contact and bending stresses and transmission error of the gear in mesh. M. Divandari et al (2012), investigated the effects of profile modifications on the reduction of gear vibrations and tooth localized defects. Root relieved teeth are more effective in reduction of vibration in gears. Ting Zou et al (2014), investigated the effect of tooth root geometry on stress concentration to increase gear tooth strength by optimizing the root profile. Circular fillet was replaced by cubic splines, which yielded better bending strength at root fillet portion of gear tooth. Daniela S. Ristic \& Janez Kramberger (2014) analyzed the impact of gear tooth fillet radius on stress value and distribution, and, focussed on finding the optimal fillet tooth root radius to minimize the tooth root stress intensity. Qian Tang et al (2014), investigated the effect of pressure angle, fillet radius and addendum coefficient have on bending strength. Decrease in addendum coefficient decreases bending stress, but it then increase with decrease in addendum coefficient under small pressure angle. Bending stress decreases with increase in addendum coefficient under high pressure angle. Jikai Fan et al (2015), proposed a kind of profile modification cubic curve of involute gear using the geometric theory and Curve fitting method. This modification curve gives smooth transition between cubic curve and involute as well as cubic curve and addendum circle. Hui Ma et al (2015) developed a mesh stiffness model for profile shifted gears with addendum modifications and tooth profile modifications. System vibration responses were analyzed under different tooth profile modification curves using FE Method.

\section{PROFILE MODIFICATIONAND GEAR MODELLING}

Profile Modification of spur gear means to modify different involute profile parameters of the gear tooth to reduce the bending stress or root fillet stress in gear tooth. These profile parameters include root radius, profile radius and face width of the gear tooth. Root radius is the fillet radius of the root fillet portion of the gear tooth. Profile Radius is the radius 
of curvature of the involute profile curve. Face width is the length of the top land perpendicular to the axis of the tooth. When two spur gears are engaged with each other, the load acts in tangential direction at the tip of the tooth and the distribution of bending stress is formed in parabolic locus. The stress distribution can be divided in three stress zone as shown in Figure 1. Stress Zone 1 is the tip of tooth, where the bending stress is minimum and stress increases from the tip to the root. The Stress Zone 3 at the root posses the maximum stress while Stress Zone 2 coversthe involute profile where the stress distribution is medium.

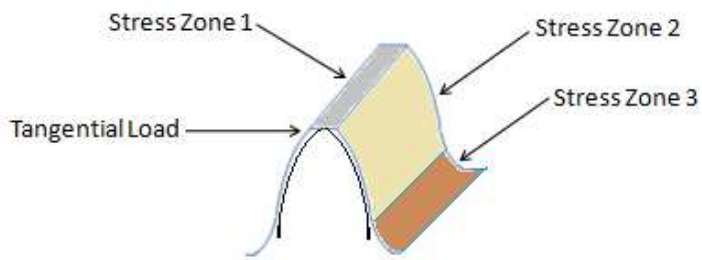

Figure 1: Stress Zones

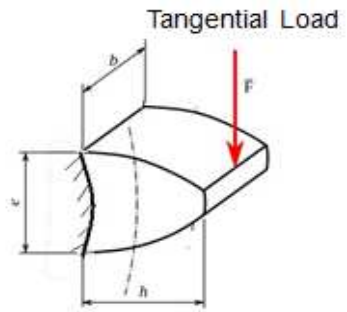

Figure 2: Lewis Gear Model

While modifying the profile parameters to achieve the desired results, the static analysis of the gear tooth is carried out using Lewis Equation. For the static analysis of gear tooth for bending stresses, radial component of force is neglected and tangential component of force is uniformly distributed over the entire face width as shown in Figure 2.

In this research, the profile modification is carried out using structural analysis software ANSYS 16.0 Workbench, and the results obtained are compared with the theoretical results obtained by Lewis theory of bending stress. Further, the three profile parameters are optimized and relationship with the stress concentration is established which helps to determine the most effective parameter in the reduction of stress concentration in the gear tooth. The CAD model of spur gear is modelled in CATIA V5using design specifications given in Table 1. The material of the gear is structural steel having modulus of elasticity 2, 00,000 MPa and Poisson's ratio 0.3.

Table 1: Gear Specifications

\begin{tabular}{|l|l|}
\hline Module, $\mathrm{m}$ & $4 \mathrm{~mm}$ \\
\hline Number of teeth, $\mathrm{Z}$ & 14 \\
\hline Radius of Pitch Circle, $\mathrm{R}_{\mathrm{p}}=\mathrm{mZ} / 2$ & $28 \mathrm{~mm}$ \\
\hline Radius of Base Circle, $\mathrm{R}_{\mathrm{b}}=0.94 \mathrm{R}_{\mathrm{p}}$ & $26.33 \mathrm{~mm}$ \\
\hline Radius of Addendum Circle, $\mathrm{R}_{\mathrm{a}}=\mathrm{R}_{\mathrm{p}}+\mathrm{m}$ & $32 \mathrm{~mm}$ \\
\hline Radius of Dedendum Circle, $\mathrm{R}_{\mathrm{d}}=\mathrm{R}_{\mathrm{p}}-1.25 \mathrm{~m}$ & $23 \mathrm{~mm}$ \\
\hline Pressure Angle, $\alpha$ & 20 degrees \\
\hline Fillet Radius, $\mathrm{R}_{\mathrm{f}}=0.39 \mathrm{~m}$ & $1.56 \mathrm{~mm}$ \\
\hline Circular Pitch, $\mathrm{p}=\pi \mathrm{D}_{\mathrm{p}} / \mathrm{Z}$ & $12.56 \mathrm{~mm}$ \\
\hline
\end{tabular}




\begin{tabular}{|l|l|}
\hline Face width, b & $5 \mathrm{~mm}$ \\
\hline
\end{tabular}

The CAD model of spur gear tooth (Figure3) is imported to ANSYS 16.0 workbench and finite element analysis is carried out to observe the concentration of bending stresses, developed in the gear tooth, running at a speed of 1000 RPM transmitting a power of $20 \mathrm{KW}$.

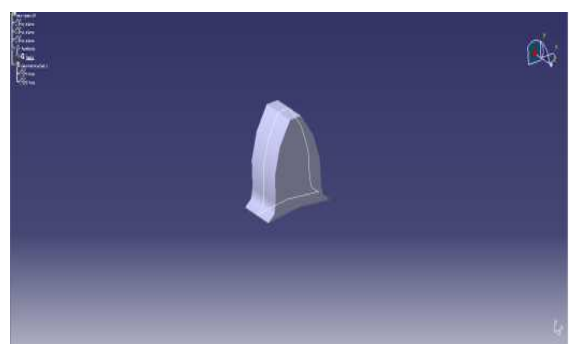

Figure 3: Spur Gear Tooth Considered for Static Analysis

The equivalent Von-Mises Stress gives the value of bending stress acting at the root of the tooth, as FEA analytical results. Von Mises stress is used because; it is the Distortion energy theory failure criterion, which predicts the failure with good level of accuracy and widely preferred for designing ductile materials. The FEA analytical results are compared with the Theoretical results of Lewis Equation for convergence or correctness of the results. The objective of this analysis is to reduce the bending stress acting at the root, which can lead to improvement in the bending strength of the gear tooth and gives higher load capacity. Bending stress reduction can lead to higher load capacity, longer lifetime, lower noise and vibration and cost reduction [Kaplevich 2009].

\section{FINITE ELEMENT ANALYSIS}

A Finite Element Model of single spur gear tooth is considered for static analysis. The spur gear tooth is meshed using 'Tetrahedron Element Mesh Method' with Patch Independent Algorithm, which can be best preferred for capturing edges and faces of dirty geometries. The element type used for the analysis is "SOLID TETRAHEDRAL 10 NODES 187" is preferred. The Meshed Model of spur gear tooth is as shown in Figure 4.The boundary condition is taken by fixing the root circle and applying the tangential load uniformly distributed over the face width as per the Lewis analysis, in ANSYS 16.0 workbench as shown in Figure 5and Figure 6. The result of analysis gives the Von-Mises stress, which is compared with the Lewis Equation result.

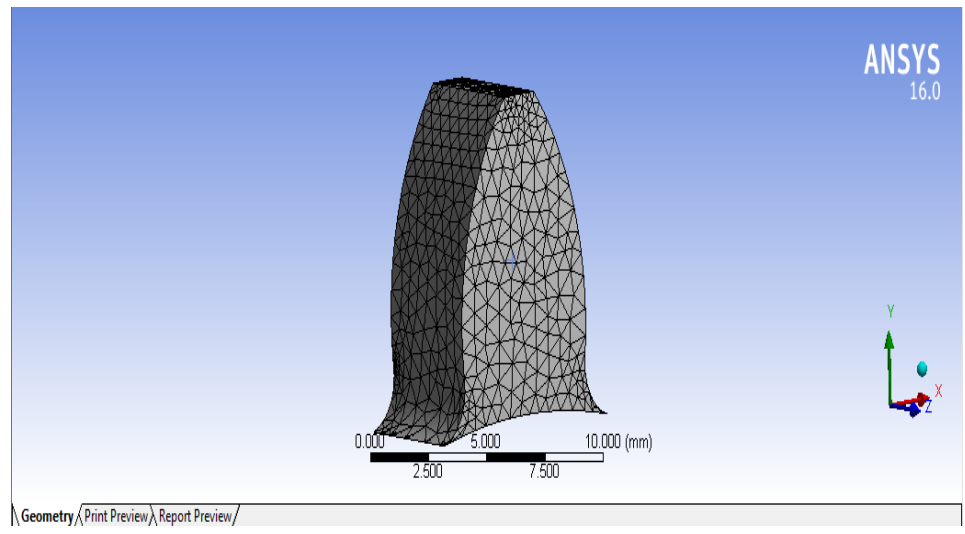

Figure 4: Meshed Model of Spur Gear Tooth 


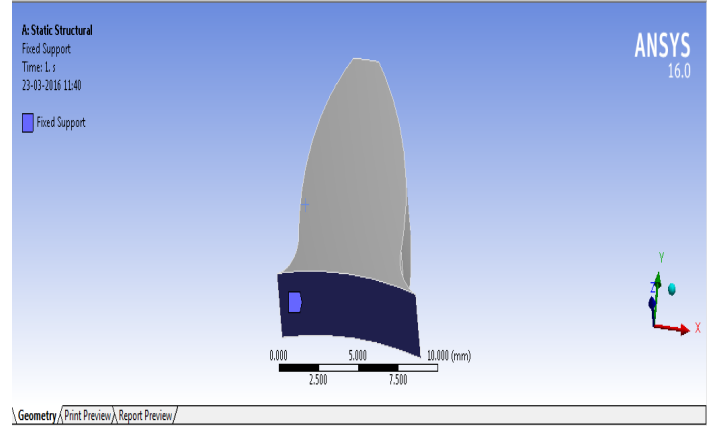

Figure 5: Applying the Boundary Conditions

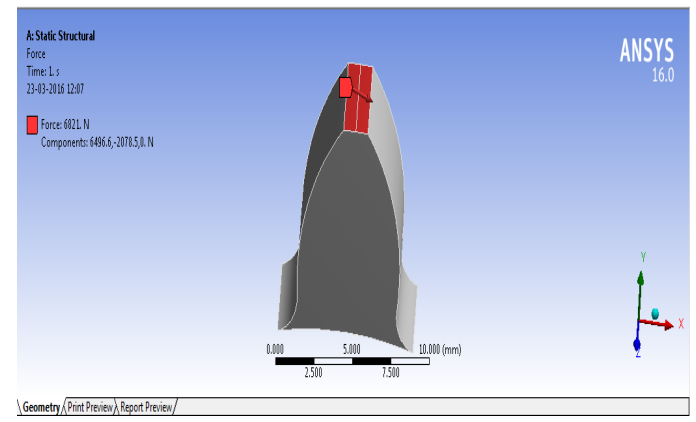

Figure 6: Applying the Tangential Load

The Tangential Load applied depends on the amount of torque transmitted. Torque depends on the amount of speed with which the gear is running and the value of power transmitted, which is given by Equation 1 and, the tangential load is given by the Equation 2 .

The spur gear tooth is running at speed of $1000 \mathrm{RPM}$ and transmitting power of $20 \mathrm{KW}$.

So, the torque it is transmitting is,

$\mathrm{T}=60 \mathrm{P} / 2 \pi \mathrm{N}$

The tangential load value depends upon the magnitude of the torque it is transmitting.

It is given by,

$P_{t}=2 T / d_{p}$

Equation 2 gives value of tangential load of $6821 \mathrm{~N}$, which is used throughout the analysis, as shown in Figure 6.The result of FEA analysis is the Von-Mises stress results, which gives the analytical bending stress which is compared to the Theoretical bending stress given by the Lewis Equation. This bending stress is to be reduced by optimizing two parameters i.e., the Root Radius and the Profile Radius.

\section{METHOD OF OPTIMIZATION}

Case 1: Optimizing Root Radius only, keeping Profile Radius\& Face width constant

Root Radius effects the bending stress of the spur gear tooth. The minimum root radius for 4 mm module spur gear is $1.56 \mathrm{~mm}$, which is increased by $0.5 \mathrm{~mm}$ from $1.06 \mathrm{~mm}$ to $4.06 \mathrm{~mm}$, keeping the Profile Radius of $9.5 \mathrm{~mm}$ and Face width of $5 \mathrm{~mm}$ as constant. 
Case 2: Optimizing Profile Radius only, keeping Root Radius \& Face width constant

In this case, the Profile Radius for $4 \mathrm{~mm}$ module gear is $9.5 \mathrm{~mm}$, which is increased from $9.5 \mathrm{~mm}$ to $10 \mathrm{~mm}$ by 0.1 $\mathrm{mm}$ difference, keeping the Root Radius of $1.56 \mathrm{~mm}$ and Face width of $5 \mathrm{~mm}$ as constant.

Case 3: Optimizing both Root Radius \& Profile Radius, keeping Face width constant

In this case, both the Root Radius from $1.56 \mathrm{~mm}$ to $4.06 \mathrm{~mm}$ and Profile Radius from $9.5 \mathrm{~mm}$ to $10 \mathrm{~mm}$ are increased simultaneously in every optimization, keeping Face width of $5 \mathrm{~mm}$ as constant.

Case 4: Optimizing Root Radius \& Face width, keeping Profile Radius constant

In this case, the Face width is to be increased from $5 \mathrm{~mm}$ to $30 \mathrm{~mm}$ along with the Root Radius, which is increased from $1.56 \mathrm{~mm}$ to $4.06 \mathrm{~mm}$ simultaneously in every optimization, keeping Profile Radius of $9.5 \mathrm{~mm}$ constant.

Case 5: Optimizing Profile Radius \& Face width, keeping Root Radius constant

In this case, the Face width is to be increased from $5 \mathrm{~mm}$ to $30 \mathrm{~mm}$ along with the Profile Radius, which is increased from $9.5 \mathrm{~mm}$ to $10 \mathrm{~mm}$ simultaneously after every optimization, keeping Root Radius of $1.56 \mathrm{~mm}$ constant.

Case 6: Optimizing Root Radius, Profile Radius \& Face width

In this case, all the parameters Root Radius increased from $1.56 \mathrm{~mm}$ to $4.06 \mathrm{~mm}$, Profile Radius from $9.5 \mathrm{~mm}$ to $10 \mathrm{~mm}$ and Face width from $5 \mathrm{~mm}$ to $30 \mathrm{~mm}$, are increased simultaneously.

After each case of optimization, the bending stress results are compared with the results of every previous case of optimization, to check the reduction of the bending stress.

\section{RESULTS \& DISCUSSIONS}

Case 1: Results of Optimization of Root Radius, keeping Profile Radius \& Face width constant

The Case 1 results are shown in Figure 7. The bending stress is maximum at the root section and it is minimum at the tip and gradually increasing from the tip to the root. At the profile zone, it is medium. The increase in the Root Radius, the bending stress is decreasing, which is compared with the theoretical bending stress and the \% correctness is taken after the comparison.

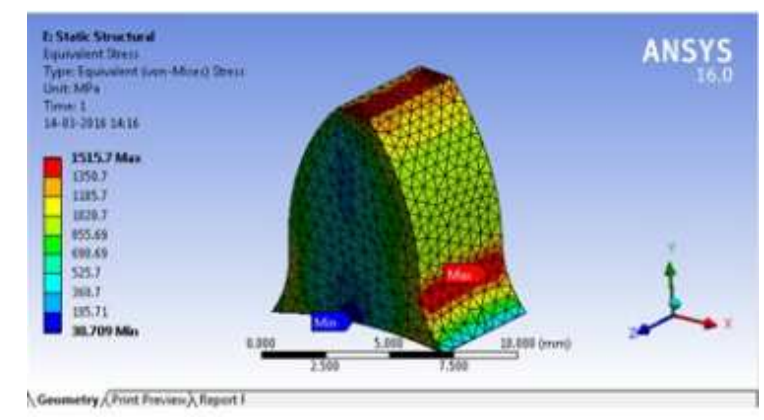

Figure 7: Root Radius Optimization

Case 2: Results of Optimization of Profile Radius, keeping Root Radius \& Face width constant 


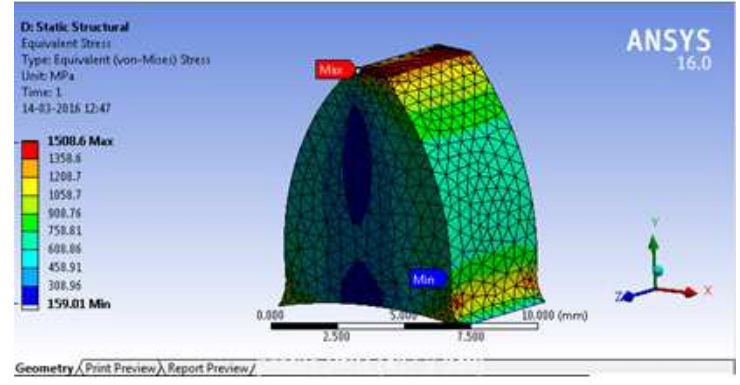

Figure 8: Profile Radius Optimization

The Case 2 results are shown in Figure 8. When only profile radius is increased, keeping the root radius constant, it is observed that there is an increase in the thickness of the tooth, due to which the root portion is being modified. This lead to the shifting of the maximum bending stress portion to the tip of the tooth the increase in the profile radius resulted in better reduction of bending stress compared to the Case 1.

Case 3: Results of Optimization of Both Profile Radius \& Root Radius, keeping Face width constant

The Case 3 results are shown in Figure 9. The increase in both the profile radius \&root radius simultaneously, resulted in better reduction of bending stress compared to the Case 2 and even better than Case 1, and there is large thickness of tooth, which reduced the root portion, leading to the shifting of bending stress at the tip.

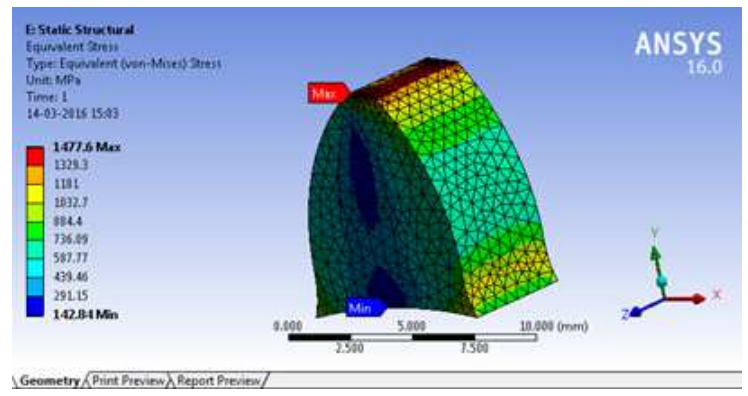

Figure 9: Profile Radius \& Root Radius Optimization

Case 4: Results of Optimization of Root Radius \& Face width, keeping Profile Radius constant

The Case 4 results are shown in Figure 10. When Face width is increased along with increase in Root Radius, it is observed that there is a tremendous decrease in the bending stress compared to the above three Cases.

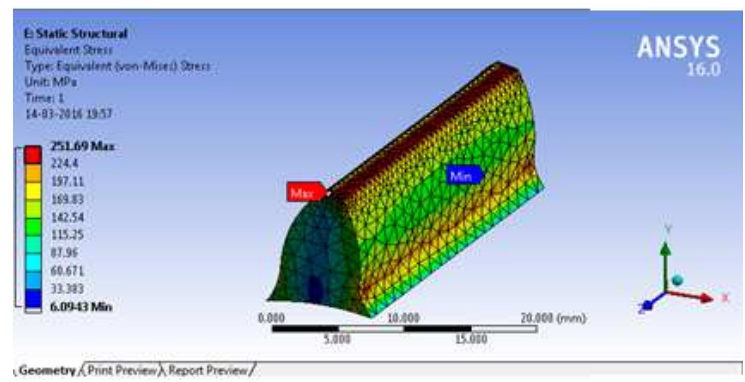

Figure 10: Root Radius \& Face width Optimization

Case 5: Results of Optimization of Profile Radius \& Face width, keeping Root Radius constant 
The Case 5 results are shown in Figure 11. When face width is increased along with increase in profile radius, it is observed that the bending stress reduction was much higher than the Case 4 optimization.

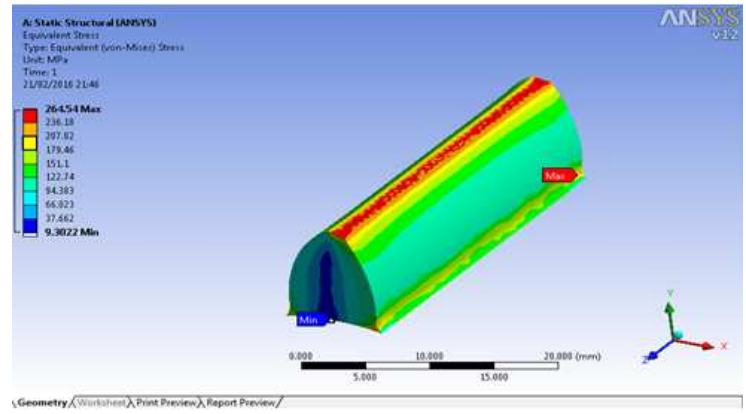

Figure 11: Profile Radius and Face width Optimization

Case 6: Results of optimization of all three parameters; Root Radius, Profile Radius \& Face width

The Case 6 results are shown in Figure 12. The increase in the entire parameters root radius, profile radius and face width simultaneously, it is observed that the bending stress reduction is maximum in this case, compared to all other previous Cases.

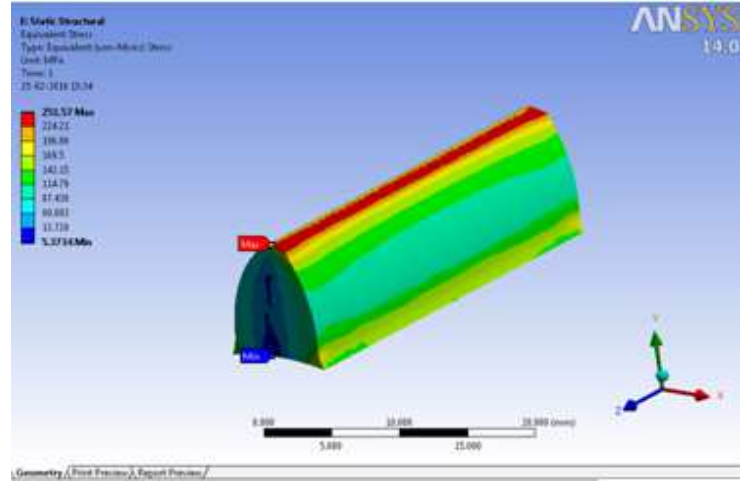

Figure 12: Profile Radius, Root Radius and Face width Optimization

The comparison of bending stress variation taking root radius along with other parameters are shown in Figure 13 and the comparison of bending stress taking profile radius with other parameters are shown in Figure 14.

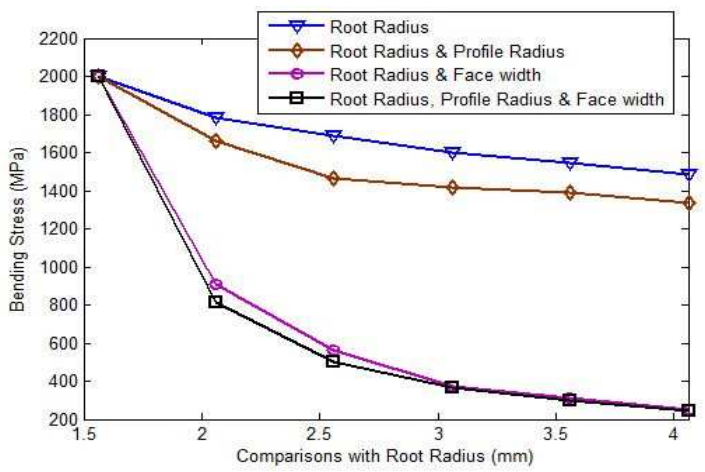

Figure 13: Comparison of Bending Stress taking Root Radius with other Parameters 


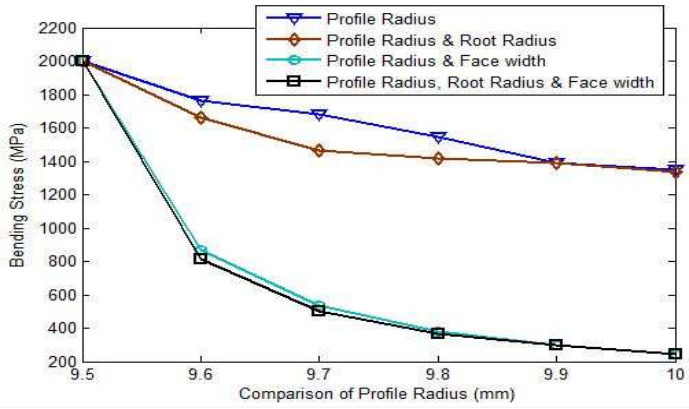

Figure 14: Comparison of Bending Stress taking Profile Radius with other Parameters

The following conclusions can be revealed from the Figure 13 and Figure 14:

- There was much reduction in bending stress of spur gear tooth, when the Profile Radius was optimized rather than optimization of Root Radius.

- On comparing the Root Radius optimization and Profile Radius optimization with the Root Radius and Profile Radius optimization, the reduction of bending stress was more with Profile Radius rather than Root Radius.

- In the both cases, when Face width was introduced with Root Radius as well as Profile Radius, there was much higher reduction of bending stress in spur gear tooth.

- But, the difference in bending stress reduction was slightly higher, when taking Profile Radius with Face width rather than Root Radius with Face width.

- The difference in bending stress reduction between the case of taking Root Radius \& Face width and the case of taking all three parameters was quite high as observed in Figure 13, compared to the difference in bending stress reduction between the case of taking Profile Radius \& Face width with the case of optimizing all three parameters as observed in Figure 14.

\section{CONCLUSIONS}

In the present work, the profile modification of a spur gear tooth is carried out considering three tooth profile parameters, Root Radius, Profile Radius and Face width, to reduce the bending stress of the gear tooth. The analysis shows that the Profile Radius modification yields better improvement in stress concentration when compared to the results obtained by Root Radius modification. Further, it is observed that, when the third parameter, Face width is increased along with Profile Radius or Root Radius, there is tremendous reduction in the bending stress compared to the previous cases. Optimizing Face width along with Profile Radius gave better results than Optimizing Face width along with Root Radius. Finally, optimizing all three parameters simultaneously, yielded maximum reduction of bending stress compared to all above cases. It is concluded that the Face width is the best parameter in the bending stress analysis, after which comes Profile Radius and last the Root Radius.

\section{REFERENCES}

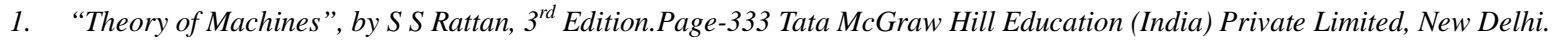

2. Giorgio Bonori, Marco Barbieri, Francesco Pellicano, Optimum Profile Modifications of Spur Gears by means of Genetic Algorithms. Journal of Sound and Vibration 313 (2008). Science Direct. 
3. V.Senthil Kumar, D.V.Muni, G. Muthuveerappan, Optimization of asymmetric spur gear drives to improve the bending load capacity. Mechanism and Machine Theory. Science Direct,2008.Vol.23

4. Shanming Luo, Yue Wu, Jian Wang, The generation principle and mathematical models of a novel cosine gear drive. Mechanism and Machine Theory 43 (2008)

5. Jian Wang, Shanming Luo and Shimin Zhu, Initiative Design of Tooth Profiles with Small Sliding Coefficients. Applied Mechanics and Materials Vols. 16-19 (2009)

6. Kapelevich and Y. Shekhtman, Tooth Fillet Profile Optimization for Gears with Symmetric and Asymmetric Teeth. www.geartechnology.com, September/October 2009, Gear Technology

7. V.Spitas, C.Spitas \& T.Costopoulos, Reduction of Tooth Fillet Stresses Using Novel One-Sided Involute Asymmetric Gear Design. Mechanics Based Design of Structures and Machines. 14 May (2009).

8. Vilmos Simon, Optimal Modifications of Gear Tooth Surfaces. Proceedings of $3^{\text {rd }}$ International Conference on Power Transmission 2009. October 1-2, 2009, Chalkidiki, Greece.

9. I.D. Paul and G.P. Bhole, Modification of Spur Gear Using Computational Method-Involutes Profile Being Modifiy. Proceedings of the 2010 International Conference on Industrial Engineering and Operations Management, Dhaka, Bangladesh, January 9-10, 2010.

10. S.Sankar, Maasanamuthu Sundar Raj and Muthusamy Nataraj, Profile Modification for Increasing Tooth Strength in Spur Gears using CAD. The International Journal of Advanced Manufacturing Technology (2010), 55 (1-4): 1-10.

11. M. Divandari, B.H. Aghdam and R. Barzamini, Tooth Profile Modification and its Effect on Spur Gear Pair Vibration in Presence of Localized Tooth Defect. Journal of Mechanics (2012).

12. Ting Zou, Jorge Angeles, Mathew Shaker, Alexei Morozov, Optimization of Tooth Root Profile of Spur Gears for maximum Load carrying capacity. Proceedings of the ASME 2014 International Design Engineering Technical Conferences \& Computers \& Information in Engineering Conference IDETC/CIE 2014 August 17-20, 2014, Buffalo, New York, USA.

13. Daniela S. Ristić, Janez Kramberger, Gear Tooth Root stress and Fillet Radii Dependence.FME Transactions(2014) Vol. 42, 323-328.

14. Qian tang, Xiaofeng Jin, Qiulei Fan, Parametric Coordination and Simulation Study on Nonstandard Spur Gears. Jordan Journal of Mechanical and Industrial Engineering (JJMIE), Vol.8, Number 2, April 2014.

15. Jikai Fan, Yanlei Li, Xiong Jing, XiaokunDuan, Improvements researches on involute tooth profile. $11^{\text {th }}$ World Congress on Structural and Multidisplinary Optimisation.0 $7^{\text {th }}-12^{\text {th }}$ June 2015, Sydney, Australia.

16. Hui ma, Xu Pang, RanjioFeng, Bangchun Wen, Evaluation of optimum profile modification curves of profile shifted spur gears based on vibration responses. Mechanical Systems and Signal Processing

17. V B Bhandari, Design of Machine Elements $3^{\text {rd }}$ Edition. Spur Gears pp: 646-680. 